\title{
NUEVOS DERECHOS FRENTE A LA NEUROTECNOLOGÍA: LA EXPERIENCIA CHILENA
}

NURIA RECHE TELLO 


\section{SUMARIO}

1. INTRODUCCIÓN. 2. EL ORIGEN DE LOS NEURODERECHOS. 3. CHILE, EL PIONERO EN REGULAR LOS NEURODERECHOS. 3.1. La iniciativa de reforma constitucional. 3.1.1. El primer trámite constitucional: la deliberación y aprobación ante el Senado. 3.1.2. El segundo trámite constitucional: la deliberación y aprobación ante el Congreso 3.2. El proyecto de Ley sobre protección de los neuroderechos. 3.2.1. El contenido introductorio. 3.2.2. Los objetivos de la ley. 3.2.3. Las definiciones. 3.2.4. Las prohibiciones legales y los límites del consentimiento. 3.2.5. Límites y obligaciones estatales ante el desarrollo de las neurotecnologías. 4. REFLEXIONES FINALES. 


\title{
NUEVOS DERECHOS FRENTE A LA NEUROTECNOLOGÍA: LA EXPERIENCIA CHILENA
}

\author{
NURIA RECHE TELLO ${ }^{1}$ \\ Universidad Miguel Hernández de Elche (Alicante)
}

\section{INTRODUCCIÓN}

El desarrollo científico y tecnológico logrado a lo largo de las dos primeras décadas del siglo XXI ha sido de tal magnitud que cuesta hacerse a la idea de cómo serían nuestras vidas actualmente sin teléfono móvil, internet o redes sociales. El uso de estas herramientas, que ha supuesto una conexión infinita de personas y cosas a través de la red, ha generado lo que se conoce como el Big Data, un volumen inmenso de datos personales que las grandes corporaciones, incluso los propios Estados, han empezado a codiciar por su capacidad para generar negocios estratégicos, pero también como mecanismo de control de la población. Con el fin de gestionar esta cantidad ingente de información se han sofisticado los sistemas de Inteligencia Artificial (IA), gobernados por algoritmos que día a día se van implementando en la toma de decisiones, tanto en el sector privado como en el público. El nuevo panóptico digital ${ }^{2}$ en la era del Big Data constituye un eficiente instrumento psicopolítico que permite intervenir en la mente, condicionándola a un nivel prerreflexivo, e incluso hacer pronósticos sobre el comportamiento humano, de manera que el futuro se convierte así en predecible y controlable.

Por si todo esto no fuera suficiente, la neurociencia, sobre todo en la última década, ha iniciado la carrera para descifrar el funcionamiento del cerebro humano, lo que permitirá no sólo entendernos mejor, sino también progresar en el tratamiento de enfermedades mentales o neurodegenerativas, así como crear grandes oportunidades en el plano económico ${ }^{3}$. A su vez, se están desarrollando toda una serie de neurotecnologías

1 Profesora Ayudante Doctora de Derecho Constitucional (acreditada Contratada Doctora) en Universidad Miguel Hernández de Elche, Av. de la Universidad s/n. Edificio Torrevaillo, 03202 Elche (Alicante),nuria.reche@umh.es.

BYUNG-CHUL H. (2020). Psicopolítica, Barcelona, Herder, pp. 25-26.

3 YUSTE, R. (2019). «Las nuevas neurotecnologías y su impacto en la ciencia, medicina y sociedad», en Lecciones Cajal 01, Universidad de Zaragoza. 
que posibilitarán leer y escribir en nuestras mentes. Diferentes empresas privadas ya están invirtiendo miles de millones en técnologías de carácter no invasivo, que permitirán conectar nuestro cerebro con internet mediante una interfaz cerebro-computador (ICC), una especie de «iphone cerebral» que anuncia un negocio sin precedentes por sus prestaciones, entre ellas la promesa de aumentar nuestras capacidades cognitivas.

Los peligros que para los derechos humanos suponen todos estos avances tecnológicos ya han sido advertidos desde la ética que, aun con sus limitaciones a la hora de ofrecer respuestas a tales retos, ha iniciado una nueva relación con la tecnología adquiriendo mayor relevancia respecto al siglo anterior. Concretamente, la preocupación por los problemas éticos arranca en la reunión celebrada en mayo de 2002 en San Francisco (California), un congreso patrocinado por la Dana Foundation y organizado por las Universidades de Stanford y California, que reunió a unos 150 especialistas de muy diversos campos para estudiar y analizar las implicaciones éticas y sociales de la investigación sobre el cerebro. Surge así la neuroética ${ }^{4}$ como «el examen de lo que es correcto o incorrecto, bueno o malo, acerca del tratamiento, perfeccionamiento, invasiones o manipulaciones del cerebro humano», en la descripción dada por Saphire en 2002. Una disciplina dividida en dos categorías: la primera, que tiene que ver con los criterios éticos de experimentación y de aplicación clínica de la neurociencia, configurándose como una rama especializada de la bioética; la segunda, que contempla a un nivel más profundo los problemas filosóficos que la neurociencia cuestiona, como el análisis de la libertad, la responsabilidad jurídica y moral, la privacidad de la persona, o la autenticidad de las emociones como personales y propias, etc. Será esta segunda vertiente la que inicie el camino por el reconocimiento de los «neuroderechos».

No obstante, esta ruta debe trazarse de la mano del derecho. Ambas disciplinas comparten un mismo objetivo, el conocimiento sobre el comportamiento humano en la consecución del bien común. A su vez, son múltiples las implicaciones jurídicas de las neurociencias: los límites que deben establecerse en las actuaciones que se realizan sobre el cerebro humano, su uso en los procesos judiciales, el neuromejoramiento, etc. En todo caso, el principio universal del respeto a la dignidad de la persona y el libre desarrollo de la personalidad, así como de los derechos inherentes a ella, deberá ser la guía, teniendo en cuenta tanto los aspectos éticos, sociales y jurídicos. Derechos fundamentales como la propia vida, la integridad física y psíquica, la libertad, la identidad o la privacidad pueden verse amenazados por un mal uso ${ }^{5}$, por lo que cualquier regulación, al mismo tiempo que favorece el desarrollo científico, habrá de ser compatible con el respeto a estos derechos fundamentales. Desde una visión humanista, la persona no es solo cerebro y mente, es un ser social, de ahí la razón de ser del derecho que se ocupa de regular la pacífica convivencia y resolver los conflictos.

4 SÁNCHEZ MIGALLÓN, S. (2009). «Neuroética», Enciclopedia filosófica on line Disponible en: http://www.philosophica.info/archivo/20092008/voces/neuroetica.

5 GARCÍA GÓMEZ, A., ABELLÁN SALORT, J. C. (2019). «Derechos humanos, libre albedrío y neuroética. Retos biojurídicos de las neurotecnologías emergentes», Medicina y Ética $\mathrm{n}^{\circ} 3$. 


\section{EL ORIGEN DE LOS NEURODERECHOS}

El punto de partida tiene lugar en el año 2017. En el mes de mayo, el Morningside Groupe, un equipo interdisciplinario de científicos, se reúne en la Universidad de Columbia, New York, en un taller de tres días patrocinado por la National Science Foundation y codirigido por el neurobiólogo español Rafael Yuste para abordar y discutir sobre los riesgos y problemas éticos derivados de las neurotecnologías y la IA, alertados por la insuficiencia de pautas en este ámbito. Del taller surge la idea de un nuevo marco de derechos humanos, al que denominan «neuroderechos».

En el plano teórico son dos los artículos científicos que constituyen el punto de partida, o el fundamento sobre la necesidad de su reconocimiento.

Por una parte, Ienca y Andorno ${ }^{6}$ reflexionan sobre la necesidad de reconceptualizar ciertos derechos humanos clásicos, así como de incorporar derechos neuroespecíficos para regular los usos indebidos de las neurotecnologías y la implicación que éstas puedan tener en diversos aspectos sustanciales de la vida humana, al tiempo que buscan proteger las libertades fundamentales asociadas con la toma de decisiones individuales en este nuevo contexto. Proponen el reconocimiento de cuatro nuevos derechos:

- Derecho a la libertad cognitiva, con dos vertientes: la positiva, para que las personas puedan tener acceso a las neurotecnologías y sus beneficios; y la negativa, que garantice la protección frente a los usos coercitivos y sin consentimiento de estas técnicas.

- Derecho a la privacidad mental, ya que aunque en la Declaración Universal de los Derechos Humanos (DUDH) se reconoce el derecho a la privacidad, no queda claro si éste incluye la protección de los datos contenidos y generados por nuestros cerebros.

- Reconceptualización del derecho a la integridad mental, para garantizar que el uso de las neurotecnologías no haga daño a su portador.

- Derecho a la continuidad psicológica, que pretende preservar la identidad personal y la coherencia del comportamiento del individuo frente a modificaciones no autorizadas por terceros. De esta forma, al proteger el funcionamiento neuronal subyacente, se protegería la continuidad de los pensamientos, preferencias y elecciones habituales de la persona.

Conocedores en profundidad de los desarrollos neurotecnológicos y sus implicaciones y riesgos, que exponen de manera detallada, concluyen que los derechos

6 IENCA M., ANDORNO R. (2017). «Towards new human rights in the age of neuroscience and neurotechnology», Life Sciences, Society and Policy, ${ }^{\circ}$ 13:5. 
humanos ahora existentes «podrían no ser suficientes», por lo que urge afrontar su regulación a la mayor brevedad para evitar consecuencias negativas.

Por otra, Yuste y Goering ${ }^{7}$ plantean una serie de recomendaciones relacionadas con cuatro áreas específicas de preocupación vinculadas con estas tecnologías y la IA: privacidad y consentimiento, identidad y agencia, aumento, y sesgo. Estas, a su vez, habrían de trasladarse en forma de cinco nuevos derechos humanos, los neuroderechos, a la DUDH incluso desarrollarse en un tratado internacional ${ }^{8}$, si bien los gobiernos deberán crear sus propios órganos deliberantes para debatir, y finalmente proponer, leyes y regulaciones específicas. La NeuroRights Initiative?, auspiciada por el Centro de Neurotecnología de la Universidad de Columbia, será la organización encargada de canalizar la propuesta de Yuste a fin de desarrollar una guía ética adicional para la innovación neurotecnológica colaborando con los legisladores de los países e incorporando la ciencia a la gobernanza. Los cinco neuroderechos serán:

- Derecho a la identidad personal, con el propósito de prohibir que tecnologías externas alteren el concepto de uno mismo.

- Derecho al libre albedrío, para establecer la necesidad de que las personas tengan el control de sus propias decisiones, sin la manipulación de neurotecnologías externas.

- Derecho a la privacidad mental, para preservar la privacidad de los datos obtenidos de la actividad neuronal, además de regularse estrictamente la venta y el uso de los mismos.

- Derecho al acceso equitativo al aumento o mejora cerebral, para toda la ciudadanía.

- Derecho a la protección contra sesgos en los algoritmos y la IA.

Además, Yuste ${ }^{10}$ propone otras medidas complementarias. La primera, que las compañías que fabriquen estas tecnologías se adhieran a un «juramento tecnocrático», similar al juramento hipocrático. La segunda, en el ámbito de la ingeniería, consistiría en desarrollar tanto hardware como software que mantenga la privacidad de los datos cerebrales obtenidos a través de una ICC, siendo posible compartir únicamente cierta información, pero no otra.

Actualmente en el ámbito internacional las únicas iniciativas aprobadas son la Recomendación de 11 de diciembre de 2019 sobre Innovación Responsable en

\footnotetext{
7 YUSTE, R., GOERING, S. (2017). «Four ethical priorities for neurotechnologies and AI», Nature $\mathrm{n}^{\circ} 159$

8 YUSTE, R. et al. (2021). «It's time for Neuro-Rights?», Horizons n ${ }^{\circ}$ 18, disponible en: https:// www.cirsd.org/en/horizons/horizons-winter-2021-issue-no-18/its-time-for-neuro--rights.

9 Disponible en: https://nri.ntc.columbia.edu/content/about

10 YUSTE, R. (2020). «La revolución del neurocapitalismo», El País Ideas, 16 de agosto.
} 
Neurotecnologías de la Organización para la Cooperación y el Desarrollo Económi$\cos (\mathrm{OCDE})^{11}$ que invita tanto a los poderes públicos como a empresas y desarrolladores a anticiparse y afrontar los déficits éticos, jurídicos y sociales que puedan surgir; y la Declaración del Comité Jurídico Interamericano «Neurociencia, Neurotecnologías y Derechos Humanos: Nuevos Desafíos Jurídicos para las Américas» de 4 de agosto de 2021, que establece un documento de principios que pueda marcar estándares internacionales a fin de orientar y armonizar las regulaciones nacionales necesarias, así como llamar la atención de los Estados, sector privado, academia y mundo científico instándolos a participar en la adopción de medidas que permitan que estas innovaciones contribuyan al bienestar de las personas y comunidades.

En el plano estatal, son dos los países que, asesorados por Yuste, ya han considerado la necesidad de regular y han dado los primeros pasos: Chile y España. En el caso de Chile, país pionero, se ha presentado una enmienda al artículo 19 n $^{\circ} 1$ de la Constitución, que contempla el derecho a la vida y a la integridad física y psíquica de la persona, así como un proyecto de Ley que la desarrolla. En el caso de España, el Gobierno ha aprobado en julio de 2021 la Carta de Derechos Digitales incorporando en su apartado vigésimo sexto los «Derechos digitales en el empleo de las neurotecnologías».

En este artículo nos proponemos realizar un análisis del proceso fundador de regulación chileno, aún en construcción, pero que consideramos en cualquier caso un buen ejercicio de partida para el debate sobre el cómo, el cuándo, el porqué y el para qué de su reconocimiento.

\section{CHILE, EL PIONERO EN REGULAR LOS NEURODERECHOS}

Como decíamos, los planteamientos teóricos acerca de los neuroderechos han encontrado acogida por parte del Estado chileno, que se sitúa como el primer país en incorporar estas propuestas de la ciencia a la gobernanza.

Hay que remontarse a 2019 cuando Yuste presentaba en enero su propuesta en el Congreso Futuro y, en abril, en la Universidad Católica. Seguidamente, el 28 de mayo, el senador Girardi anunciaba públicamente la colaboración con la Neuroright Initiative y, el 2 de octubre de 2019, se concretaba en una propuesta de reforma constitucional. Un año más tarde, los senadores Girardi, Goic, Chahuán, Coloma y De Urresti, presentaban, por un lado, un proyecto de reforma constitucional que modifica el artículo 19, $\mathrm{n}^{\circ}$ 1, de la Carta Fundamental, para proteger la integridad y la indemnidad mental en relación con el avance de las neurotecnologías (Boletín $\mathrm{N}^{\circ}$ 13827-19); por otro, un proyecto de Ley sobre protección de los neuroderechos y la integridad mental, y el desarrollo de la investigación y las neurotecnologías (Boletín $\mathrm{N}^{\circ}$ 13828-19). Ambos documentos fueron respaldados por la Comisión de Desafíos

11 Disponible en: https://www.oecd.org/fr/sti/tech-emergentes/recommandation-innovation-responsable-dans-le-domaine-des-neurotechnologies.htm

(C) UNED. Revista de Derecho Politico

N. ${ }^{\circ} 112$, septiembre-diciembre 2021, págs. 415-446 
del Futuro, Ciencia, Tecnología e Innovación del Senado, a finales de noviembre de 2020. Con 39 votos a favor, se aprobó la propuesta de legislar sobre los dos proyectos. A lo largo de este apartado estudiaremos su evolución teniendo en cuenta los informes presentados, así como las indicaciones o enmiendas a los textos iniciales.

Ambas iniciativas se enmarcan, a su vez, en el actual proceso constituyente que está viviendo Chile, fruto del acuerdo de la mayoría de los partidos políticos, para la redacción de una nueva Constitución Política, que fue sometido a plebiscito nacional el 25 de octubre de 2020, donde la ciudadanía decidió mayoritariamente elaborar una nueva Constitución, optando para ello por una Convención Constitucional formada por el cien por cien de ciudadanos y ciudadanas electos exclusivamente para dicho fin. Una vez redactado el nuevo texto, un plebiscito ratificatorio, previsto para 2022, definirá si la actual Constitución de 1980 es reemplazada por la nueva Carta Fundamental.

\subsection{La iniciativa de reforma constitucional}

El proyecto de reforma, Boletín $n^{0} 13.827-19^{12}$, propone una modificación del artículo $19 \mathrm{n}^{\circ} 1$, que contempla actualmente el derecho a la vida y a la integridad física y psíquica. Hay que señalar que la actual Constitución, en su artículo 127, dispone que cualquier modificación del Capítulo III «De los Derechos y los Deberes Constitucionales», artículos 19 al 23, deberá ser aprobado por las dos terceras partes de los diputados y senadores en ejercicio.

La reforma quiere establecer la consagración de un «derecho a la neuroprotección» en el texto constitucional para proteger la integridad y la indemnidad cerebral y mental con relación al avance de las neurotecnologías, incorporando para ello algunos elementos esenciales. Concretamente se introduce lo siguiente:

«Artículo único. Intercálase el siguiente inciso segundo, nuevo, en el artículo 19, $\mathrm{n}^{\circ} 1$, de la Constitución Política de la República, pasando el actual inciso segundo a ser tercero, y así sucesivamente:

«La integridad física y psíquica permite a las personas gozar plenamente de su identidad individual y de su libertad. Ninguna autoridad o individuo podrá, por medio de cualquier mecanismo tecnológico, aumentar, disminuir o perturbar dicha integridad individual sin el debido consentimiento. Solo la Ley podrá establecer los requisitos para limitar este derecho y los que debe cumplir el consentimiento en estos casos».

Desde su ingreso el 7 de octubre de 2020, el proyecto se ha sometido a discusión en la Comisión de Desafíos del Futuro del Senado, habiendo sido el texto inicial objeto de modificaciones. Así, el 4 de diciembre de 2020, se presentó por parte de la Comisión un primer informe y el 22 de enero se presentaron indicaciones durante la

12 Disponible en: https://www.senado.cl/appsenado/templates/tramitacion/index.php?boletin_ ini $=13827-19 \#$ 
discusión en general. En el boletín de 25 de enero se recogen tres propuestas de modificación, las cuales fueron aprobadas, a su vez con diversos cambios, en un segundo informe el 13 de abril. Finalmente, el 21 de abril el Senado, por mayoría, aprobaba el nuevo texto cuyo contenido variaba respecto del inicial, remitiéndose a continuación a la Cámara del Congreso para el segundo trámite constitucional. Así, el 22 de abril se iniciaba este segundo trámite dándose cuenta a la Comisión de Futuro, Ciencias, Tecnología, Conocimiento e Innovación de dicha Cámara. Fruto de esa primera discusión en la Comisión del Congreso es el informe de 31 de mayo, así como las indicaciones o enmiendas realizadas al texto de reforma constitucional el 3 de junio $^{13}$.

El proyecto de reforma constitucional justifica en la exposición de motivos la necesidad de releer conceptos jurídicos tradicionales a la luz de las nuevas tecnologías considerando oportuno «replantear el ámbito iusfundamental de ciertas garantías fundamentales en aras de dar respuestas satisfactorias frente a las nuevas amenazas que el avance científico y tecnológico envuelve». Considera necesario preservar la dignidad humana desde la protección del cerebro, buscando tutelar «que una regulación sobre este tipo de tecnologías quede en manos de un proceso de discusión social que posibilite a la nación sopesar los alcances cognitivos, emocionales y compartimentales que pueden ocasionar las neurotecnologías en los seres humanos».

Su objetivo, por tanto, es que el concepto de integridad psíquica resuma elementos tales como privacidad, libertad, consentimiento, dignidad e identidad de la persona, y que estos luego sean desarrollados en la ley. Es decir, que los neuroderechos pasen a formar parte del contenido esencial de este nuevo «derecho a la neuroprotección», como se denomina en el proyecto de reforma, y que se vincula directamente con la dignidad humana. En su vertiente de derecho de libertad, se traduce en el derecho de las personas a rechazar ataques o transgresiones arbitrarias; al mismo tiempo, en su vertiente prestacional, prevé toda una serie de acciones por parte del Estado para brindar dicha protección. Sin embargo, la propuesta, como veremos, más que establecer un nuevo derecho o redimensionar otros, aborda una específica tutela de derechos ya existentes frente a las neurotecnologías, de ahí la necesidad de delimitar bien su contenido desde el punto de vista de la dogmática de los derechos fundamentales.

\subsubsection{El primer trámite constitucional: la deliberación y aprobación ante el Senado}

Como avanzábamos, en el proceso de deliberación ante el Senado se han presentado dos informes por parte de la Comisión de Desafíos del Futuro. El primero, de 4 de diciembre de 2020, resulta muy interesante ya que recoge dudas y cuestiones planteadas por la comunidad científica al proyecto de reforma constitucional. A su vez, el Documento de Trabajo no 5 elaborado por la Universidad Autónoma de Chile,

13 Disponible en: https://www.camara.cl/legislacion/ProyectosDeLey/tramitacion.aspx?prmI$\mathrm{D}=14384 \&$ prmBOLETIN $=13827-19$

(C) UNED. Revista de Derecho Politico

N. ${ }^{\circ} 112$, septiembre-diciembre 2021, págs. 415-446 
aporta comentarios y propuestas de mejora que igualmente merecen ser tenidos en consideración.

A la pregunta general de por qué legislar, ya que hasta la fecha no existe ningún país, ni tratados o convenios internacionales que contengan regulación acerca de neuroderechos, Colombara ${ }^{14}$ recuerda que el derecho va siempre detrás del desarrollo de la sociedad y de las necesidades de regulación legal, por lo que el hecho de que ningún país lo haya abordado aún no significa que no se pueda llevar a cabo. En cuanto a cómo legislar, la propuesta de Chile parte de la inclusión del derecho a la neuroprotección como una garantía constitucional, y su desarrollo legal contempla, entre otras cuestiones, una serie de definiciones para que la ciudadanía y el poder judicial cuenten con un marco básico común sobre el que operar. Al mismo tiempo precisa que estos neuroderechos han de tener su reflejo en declaraciones, tratados y convenciones internacionales.

Respecto a su ubicación constitucional surge cierta controversia, ya que no está claro si debería integrarse en el apartado relativo a la integridad física y psíquica, en vez de en el relativo a la privacidad. Colombara ${ }^{15}$ argumenta que existen razones fundadas para vincularlo a la intimidad, puesto que los datos cerebrales se enfrentan a un riesgo de invasión en la privacidad mental, tanto por una corporación como por un Gobierno que puedan conocer sin consentimiento aquello que está en la mente, de ahí que la primera idea que se plantea sea vincularlo efectivamente a la idea de privacidad o intimidad mental. Sin embargo cree que su vinculación con la integridad física y psíquica tendría un mayor alcance, puesto que al ser factible que, como han revelado neurocientíficos en sus experimentos, no solo será posible violar la privacidad mental, sino también reescribir dicha actividad para que la persona haga, sienta o piense algo determinado, se iría más allá de la privacidad afectando a la integridad misma de la persona y a su libre albedrío, que es la capacidad de tomar las propias decisiones. Por ello, acertadamente, se introduce finalmente la reforma en el artículo $19 \mathrm{n}^{\circ} 1$ al ser la integridad, el libre albedrío, la esencia del ser humano lo que está en juego.

Entrando a valorar el contenido de la reforma, Díaz y Peredo ${ }^{16}$ consideran que la propia justificación de la necesidad de proteger la integridad humana desde el punto de vista neurológico, trascendiendo así el aspecto físico y psíquico, necesitaría una mejor delimitación y conceptualización. El actual artículo $19 \mathrm{n}^{\circ} 1$ y la jurisprudencia constitucional ya contemplan lo referente a la integridad física y psíquica, siendo necesario definirla desde el punto de vista neurobiológico, puesto que el proyecto no lo contempla, evitando redundancias con los contenidos esenciales de derechos fundamentales como la privacidad y protección de datos personales o el principio de

14 Respuesta dada en Informe de la Comisión de Desafíos del Futuro, de 4 de diciembre de 2020. 15 Ibidem.

16 DÍAZ FUENZALIDA, J.P. y PEREDO ROJAS, M. I. (2021). « ¿Cómo avanzar en los nuevos neuroderechos y en su regulación? Comentarios al proyecto de reforma constitucional (Boletín No 13827-19) y al proyecto de Ley (Boletín No 13828-19)», Documento de trabajo Instituto de Investigación en Derecho, Universidad Autónoma de Chile. 
igualdad y no discriminación. Así, proponen que se incorpore en la redacción lo siguiente: «La Constitución asegura a todas las personas: $1^{\circ}$.- El derecho a la vida y a la integridad física, psíquica y neurológica de la persona». Ello introduciría una nueva esfera de protección que estaría a la par de las dimensiones física y psíquica de la integridad personal, ampliándose así su contenido esencial, que se correspondería con lo manifestado en la exposición de motivos del proyecto determinando sus fronteras frente a la intervención estatal.

No obstante, la introducción de esta tercera faceta plantea el espinoso tema de la relación existente entre cerebro y mente, uno de los problemas más difíciles de resolver, tanto para la filosofía como para la ciencia. De ahí, como se verá, que en la redacción última del Senado se opte por no incluir esta tercera dimensión. Si bien como sostiene Yuste, «el cerebro no es un órgano cualquiera del cuerpo, sino que es el que genera la mente humana y todas las actividades mentales o cognitivas de las personas $(\ldots) »^{17}$, desde la filosofía se ha acusado a la neurociencia de un cierto reduccionismo, al abstraerse de todo lo subjetivo y centrarse únicamente en lo objetivo, por lo que su visión no abarca la totalidad de lo real ${ }^{18}$. Ello nos conduce a que la asunción de un proyecto de tal envergadura necesita abordarse interdiscipinariamente.

Sobre el consentimiento, aspecto central de la propuesta, como requisito ligado a la posibilidad de aumentar, disminuir o perturbar la integridad individual con neurotecnologías, se plantean interrogantes ${ }^{19}$ ya que, aunque la persona lo otorgase, existen una serie de cuestiones éticas que exigirían mayor reflexión. Por ejemplo, en aquellas con algún grado de discapacidad intelectual que no puedan cederlo debidamente, en cuyo caso se debería preservar la integridad evitando prácticas invasivas. Yuste $^{20}$ aclara que el consentimiento estaría regulado por la ley, aplicando el modelo médico y en conciliación con los derechos del paciente, de manera que la comercialización de dichos aparatos se regularía como si fuesen dispositivos médicos, exigiendo un consentimiento libre e informado y el resguardo de la privacidad con el mismo rigor con que se regulan el consentimiento y datos de los pacientes en los trasplantes de órganos. Pese a ello, y puesto que existen valores distintos en las diferentes culturas, coincide en que sería necesario elevar esta discusión a organismos internacionales. Por otra parte, como señalan Díaz y Peredo, la amplia posibilidad de regularlo mediante Ley podría ocasionar, de manera paradójica, que «una mayoría circunstancial en el Congreso estableciese con laxitud los requisitos para restringir la integridad de un ser humano, abriendo de este modo la puerta a la intervención estatal en materia no sólo neurológica, sino también física o psicológica, considerando la redacción

17 Respuesta recogida en el Informe de la Comisión de Futuro, Ciencias, Tecnología, Conocimiento e Innovación, de 31 de mayo de 2021.

18 RIVERA DE ROSALES, J. (2016). «Cuerpo y libertad. El experimento neurológico de Libet», Pensamiento, n. ${ }^{\circ}$ 273, pp.1019-1041.

19 Pregunta planteada por la Señora MUÑOZ en Informe de la Comisión de Desafíos del Futuro, de 4 de diciembre de 2020.

20 Respuesta en Informe de la Comisión de Desafíos del Futuro, de 4 de diciembre de 2020.

(C) UNED. Revista de Derecho Politico

N. ${ }^{\circ} 112$, septiembre-diciembre 2021, págs. 415-446 
amplia de la reserva, referida a todas estas facetas» ${ }^{21}$. Además, el valor del consentimiento ya se ha reconocido por parte del legislador, así como por la jurisprudencia del Tribunal Constitucional, siendo el propio artículo $19 \mathrm{n}^{\circ} 1$ el que establece que las personas nacen libres e iguales en derechos como un criterio fundamental para la autodeterminación. Si en la actualidad la ciudadanía puede ejecutar determinadas acciones capaces de interferir en su esfera de protección y se considera, cuando se realizan dentro del marco de lo socialmente aceptable, que no vulneran su contenido esencial y por tanto son plenamente lícitas, lo mismo debería regir para la afectación de los neuroderechos.

Otra cuestión tiene que ver con las garantías específicas, es decir, cómo tutelar efectivamente este derecho a la neuroprotección, máxime teniendo en cuenta que en la actualidad ya se está produciendo con total impunidad una manipulación en la capacidad de decidir de las personas por medio de las plataformas digitales ${ }^{22}$. En este sentido, el senador Girardi ${ }^{23}$ cree que sería útil incorporar al derecho penal internacional nuevos tipos para castigar el uso indebido de las tecnologías. Ahora bien, como ello sería a largo plazo, convendría que dichas garantías penales se introdujeran en la legislación interna, algo que hasta ahora no se ha producido, por lo que de manera complementaria debería iniciarse una reforma en el Código Penal a tal efecto.

En la tramitación ante el Senado, como anunciamos, se presentaron una serie de enmiendas a la redacción inicial, modificaciones que fueron aprobadas en un segundo informe en el mes de abril de 2021. Dicho texto, sometido nuevamente a votación, fue aprobado por un total de 39 votos a favor, resultando la redacción final como sigue:

«Artículo único.- Modifícase el número $1^{\circ}$ del artículo 19 de la Constitución Política de la República, de la siguiente forma:

1. Reemplázase, en el actual párrafo final, el punto y coma (;) por un punto aparte (.).

2. Agrégase el siguiente párrafo final, nuevo:

"El desarrollo científico y tecnológico estará al servicio de las personas y se llevará a cabo con respeto a la vida y a la integridad física y psíquica. La Ley regulará los requisitos y condiciones para su utilización en las personas, debiendo propender especialmente al resguardo de la actividad cerebral, así como la información proveniente de ella;".”.

En el siguiente cuadro se recoge la evolución de las diferentes redacciones del artículo 19 n $^{\circ} 1$ por la Comisión de Desafíos del Futuro del Senado:

1 DÍAZ FUENZALIDA, J.P y PEREDO ROJAS, M.I (2021). Cit.

22 Pregunta planteada por la senadora GOIC, en Informe de la Comisión de Desafíos del Futuro, de 4 de diciembre de 2020.

23 Respuesta en Informe de la Comisión de Desafíos del Futuro, de 4 de diciembre de 2020. 


\begin{tabular}{|c|c|c|c|}
\hline $\begin{array}{l}\text { DISPOSICIÓN } \\
\text { LEGAL VIGENTE }\end{array}$ & $\begin{array}{c}\text { TEXTO APROBADO } \\
\text { POR EL SENADO } \\
07 / 10 / 20\end{array}$ & $\begin{array}{c}\text { TRÁMITE DE } \\
\text { INDICACIONES AL } \\
\text { PROYECTO 22/01/21 }\end{array}$ & $\begin{array}{c}\text { MODIFICACIÓN } \\
\text { INTRODUCIDA Y } \\
\text { APROBADA POR } \\
\text { LA COMISIÓN } \\
14 / 04 / 21\end{array}$ \\
\hline $\begin{array}{l}\text { Artículo 19.- La } \\
\text { Constitución asegura } \\
\text { a todas las personas: } \\
1^{\circ} \text {. El derecho a la } \\
\text { vida y a la integridad } \\
\text { física y psíquica de la } \\
\text { persona. } \\
\text { La Ley protege la vida } \\
\text { del que está por nacer. } \\
\text { La pena de muerte } \\
\text { sólo podrá establecer- } \\
\text { se por delito contem- } \\
\text { plado en Ley aproba- } \\
\text { da con quór um } \\
\text { calificado. } \\
\text { Se prohíbe la aplica- } \\
\text { ción de todo apremio } \\
\text { ilegítimo; } \\
\ldots\end{array}$ & $\begin{array}{l}\text { «Artículo único. Inter- } \\
\text { cálase el siguiente inciso } \\
\text { segundo, nuevo, en el } \\
\text { artículo 19, número } 1^{\circ}, \\
\text { de la Constitución Polí- } \\
\text { tica de la República, } \\
\text { pasando el actual inciso } \\
\text { segundo a ser tercero y } \\
\text { así sucesivamente: } \\
\text { «La integridad física y psí- } \\
\text { quica permite a las personas } \\
\text { gozar plenamente de su } \\
\text { identidad individual y de } \\
\text { su libertad. Ninguna auto- } \\
\text { ridad o individuo podrá, } \\
\text { por medio de cualquier } \\
\text { mecanismo tecnológico, } \\
\text { aumentar, disminuir o per- } \\
\text { turbar dicha integridad } \\
\text { individual sin el debido } \\
\text { consentimiento. Sólo la } \\
\text { Ley podrá establecer los } \\
\text { requisitos para limitar este } \\
\text { derecho, y los requisitos que } \\
\text { debe cumplir el consenti- } \\
\text { miento en estos casos.» }\end{array}$ & $\begin{array}{l}\text { Artículo } 19 . \\
\text { La Constitución asegura a } \\
\text { todas las personas: } \\
1^{\circ} \text {. El derecho a la vida, la } \\
\text { integridad física y síquica y } \\
\text { la inviolabilidad cerebral. La } \\
\text { actividad neuronal sólo puede } \\
\text { accederse, registrarse o interve- } \\
\text { nirse en los casos previstos por } \\
\text { la Ley con el consentimiento de } \\
\text { la persona afectada o de quien } \\
\text { lo represente. } \\
\text { La Ley protege la vida del } \\
\text { que está por nacer. } \\
\text { La pena de muerte sólo } \\
\text { podrá establecerse por deli- } \\
\text { to co n t e m pl a do e n } \\
\text { Ley aprobada con quórum } \\
\text { calificado. } \\
\text { Se prohíbe la aplicación de } \\
\text { todo apremio ilegítimo. } \\
\text { El avance científico y tecnológi- } \\
\text { co estará al servicio de las per- } \\
\text { sonas y su desarrollo se llevará } \\
\text { a cabo con respeto a su vida e } \\
\text { integridad física y psíquica. } \\
2^{\circ} \text { La integridad física y psí- } \\
\text { quica abarca la protección de } \\
\text { la identidad y libertad de } \\
\text { cada persona frente a altera- } \\
\text { ciones producidas por cual- } \\
\text { quier tipo de intervención } \\
\text { médica, cualquiera sea su obje- } \\
\text { to. Ninguna autoridad o indi- } \\
\text { viduo podrá, por medio de } \\
\text { cualquier mecanismo tecnológi- } \\
\text { co, aumentar, disminuir o per- } \\
\text { turbar dicha integridad indi- } \\
\text { vidual sin el debido } \\
\text { consentimiento. Solo la } \\
\text { Ley podrá establecer los requi- } \\
\text { sitos para limitar este derecho } \\
\text { y los que debe cumplir el con- } \\
\text { sentimiento en estos casos. }\end{array}$ & $\begin{array}{l}\text { "Artículo único.- } \\
\text { Modifícase el número } \\
1^{\circ} \text { del artículo } 19 \text { de la } \\
\text { Constitución Política } \\
\text { de la República, de la } \\
\text { siguiente forma: } \\
\text { 1) Reemplázase, en el } \\
\text { actual párrafo final, el } \\
\text { punto y coma (;) por } \\
\text { un punto aparte (.). } \\
\text { 2) Agrégase el siguien- } \\
\text { te párrafo final, nuevo: } \\
\text { "El desarrollo científico y } \\
\text { tecnológico estará al servi- } \\
\text { cio de las personas y se } \\
\text { llevará a cabo con respeto } \\
\text { a la vida y a la integri- } \\
\text { dad física y psíquica. La } \\
\text { Ley regulará los requisi- } \\
\text { tos y condiciones para su } \\
\text { utilización en las perso- } \\
\text { nas, debiendo propender } \\
\text { especialmente al resguardo } \\
\text { de la actividad cerebral, } \\
\text { así como la información } \\
\text { proveniente de ella;".». }\end{array}$ \\
\hline
\end{tabular}

(C) UNED. Revista de Derecho Político

N. ${ }^{\circ} 112$, septiembre-diciembre 2021, págs. 415-446 
Como se observa, la propuesta de redacción final elimina conceptos controvertidos como 'identidad individual' o 'libertad' por la dificultad que a día de hoy sigue presentando su conceptualización, además del consentimiento, teniendo en cuenta las limitaciones con que actualmente se encuentra la libertad de consentir en el uso de las tecnologías. En su lugar, el nuevo texto parece plantear, al menos a priori, menos problemas interpretativos. Por una parte introduce un enfoque antropocéntrico que, en cierto modo, se complementa con el artículo 27.1 de la DUDH. A continuación, se remite al legislador con el fin de que regule los requisitos y condiciones para que estos avances científicos y tecnológicos se apliquen en las personas, debiendo «propender especialmente al resguardo de la actividad cerebral, así como la información proveniente de ella». No parece que la elección del término «propender» resulte muy afortunada, puesto que el propio significado del verbo, esto es, inclinarse o tender a algo, casa mal con el deber u obligación y podría ser susceptible de múltiples interpretaciones, considerando que habría sido más pertinente, en este sentido, utilizar el verbo «velar» en su significado de «observar atentamente».

\subsubsection{El segundo trámite constitucional: la deliberación y aprobación ante el Congreso}

En el segundo trámite constitucional se elaboró por la Comisión de Futuro, Ciencias, Tecnología, Conocimiento e Innovación un informe, de fecha 31 de mayo de 2021, en el que se recogen antecedentes, constancias reglamentarias previas, y un resumen del contenido previo aprobado por el Senado. Interesa detenernos ahora, exclusivamente, en el debate generado en la Comisión y los acuerdos adoptados, de los que cabe destacar tres aspectos.

Primeramente, del informe se desprende la voluntad unánime de continuar apoyando el proyecto de reforma, que se considera necesario. Así, se insiste en la necesidad de «definir la frontera de lo permisible y lo que invade la privacidad y el derecho a la dignidad de las personas» ${ }^{24}$ y avanzar en este tema para resguardar los derechos fundamentales frente al avance tecnológico ${ }^{25}$.

Seguidamente, respecto de la redacción y ubicación del proyecto, se expresa la preocupación por su contenido, puesto que no se habla de los derechos del artículo 19 $\mathrm{n}^{\circ} 1$, sino que, a propósito de estos, se establece una actuación para el desarrollo científico y tecnológico, por lo que tal vez la reforma debiera estar en un lugar distinto para que cumpla la función que se pretende. También se critica la redacción laxa, objeción que compartimos ${ }^{26}$. Por último, el texto parece relegar el resguardo de la actividad cerebral a un rango no constitucional, de forma que ello podría plantear problemas a la hora de aplicar la tutela correspondiente en el caso del uso de esa

\footnotetext{
24 Observación del Presidente de la Cámara, diputado TOHÁ.

25 Observación del Ministro de Ciencia, Tecnología, Conocimiento e Innovación, Señor COUVE.

26 Observaciones del diputado TORRES.
} 
información ${ }^{27}$. Como vemos, esta última objeción va en la línea de llevar al texto constitucional una protección específica a la integridad neurológica, como la planteada en el informe de la Universidad Autónoma de Chile.

Finalmente, se reprocha la ausencia hasta ahora en el debate de los expertos constitucionalistas sobre este tema ${ }^{28}$ por lo que probablemente en los próximos meses el Congreso requiera su intervención en el debate.

Puesto en votación general y particular, el proyecto de reforma constitucional resultó aprobado por unanimidad en la Comisión del Congreso. El 3 de junio de 2021, se remiten las indicaciones presentadas durante la discusión general en Sala por los diputados Tohá y Torres, quedando el texto, con las indicaciones como sigue:

\begin{tabular}{|c|c|}
\hline $\begin{array}{c}\text { BORRADOR DEL TEXTO FINAL } \\
\text { APROBADO EN EL SENADO 14/04/2021 }\end{array}$ & $\begin{array}{l}\text { INDICACIONES AL PROYECTO DE } \\
\text { REFORMA DEL Artículo } 19 \text { N }^{\circ} 1 \text { DE LA } \\
\text { CÁMARA DE DIPUTADOS 03/06/2021 }\end{array}$ \\
\hline $\begin{array}{l}\text { 2) Agrégase el siguiente párrafo final, nuevo: } \\
\text { «El desarrollo científico y tecnológico estará al } \\
\text { servicio de las personas y se llevará a cabo con } \\
\text { respeto a la vida y a la integridad física y } \\
\text { psíquica. La Ley regulará los requisitos y } \\
\text { condiciones para su utilización en las personas, } \\
\text { debiendo propender especialmente al resguardo } \\
\text { de la actividad cerebral, así como la información } \\
\text { proveniente de ella;». }\end{array}$ & $\begin{array}{l}\text { 2) Agrégase el siguiente párrafo final, nuevo: } \\
\text { «El desarrollo científico y tecnológico estará al } \\
\text { servicio de las personas y deberá proteger su vida e } \\
\text { integridad fúsica y psíquica, inclusive la actividad } \\
\text { cerebral e información proveniente de ella. La } \\
\text { Ley establecerá los requisitos y restricciones que } \\
\text { permitan asegurar su debido resguardo, así como las } \\
\text { condiciones para su utilización en las personas.». }\end{array}$ \\
\hline
\end{tabular}

En general, consideramos muy positiva esta nueva redacción, porque su contenido amplio posibilitaría que dicho texto se adapte, no sólo a los descubrimientos relacionados con la neurotecnología, sino también con otras tecnologías que estén por llegar, siendo plausible la perspectiva humanista que antepone la defensa de los intereses de la persona como límite de cualquier desarrollo tecnológico. El reforzamiento del texto por la Comisión del Congreso, con la incorporación de la obligación de proteger, no sólo la vida y la integridad física y psíquica, sino también la actividad cerebral e información proveniente de ella, como contenido específico de dicha integridad; así como unos mandatos de desarrollo al legislador, más taxativos y firmes, contribuyen a reforzar el texto inicial, que será un modelo a seguir en futuras modificaciones constitucionales.

El 29 de julio la Cámara aprobó el proyecto tras las modificaciones introducidas. El 10 de agosto, no obstante, la Comisión de Desafíos del Futuro del Senado rechazó la enmienda introducida por el Congreso. El principal motivo de oposición es la inclusión de la frase «inclusive la actividad cerebral» argumentando que, por una parte, da la impresión de que la actividad cerebral se añade a la integridad y a la vida,

27 DÍAZ FUENZALIDA, J.P. y PEREDO ROJAS, M.I. (2021). Cit.

28 Observación planteada por el diputado KAST. 
al tiempo que podrían interpretarse de manera restrictiva los elementos que estarían incluidos o no en ella. Se abre así un tercer trámite constitucional formándose una Comisión Mixta que deberá proponer la forma y el modo de resolver la divergencia entre ambas Cámaras.

Finalmente, el 29 de septiembre la Presidenta del Senado comunicó al Presidente de la República el resultado definitivo, tras el acuerdo de las dos cámaras de aprobar la propuesta de la Comisión Mixta, resultando el texto de la enmienda constitucional como sigue:

«Artículo único.- Modifícase el número $1^{\circ}$ del artículo 19 de la Constitución Política de la República, de la siguiente forma:

1. Reemplázase, en el actual párrafo final, el punto y coma por un punto y aparte.

2. Agrégase el siguiente párrafo final, nuevo:

"El desarrollo científico y tecnológico estará al servicio de las personas y se llevará a cabo con respeto a la vida y a la integridad física y psíquica. La ley regulará los requisitos, condiciones y restricciones para su utilización en las personas, debiendo resguardar especialmente la actividad cerebral, asi como la información proveniente de ella"».

\subsection{El proyecto de Ley sobre protección de los neuroderechos}

Al igual que la propuesta de reforma constitucional, el proyecto de Ley sobre la protección de los neuroderechos y la integridad mental, y el desarrollo de la investigación y las neurotecnologías, tuvo entrada el 7 de octubre de 2020 en la Comisión de Desafíos del Futuro del Senado de Chile, presentándose un informe de objeciones al mismo en diciembre de 2020. Actualmente, el proyecto de Ley se encuentra pendiente de votación por la Cámara del Senado, habiéndose presentado enmiendas el pasado 8 de abril.

Junto con la introducción, el contenido recoge diez artículos repartidos en tres títulos: un primero de disposiciones generales, un segundo de medidas para proteger la integridad y privacidad mental, y un tercero dedicado al desarrollo de la investigación y el avance de las neurotecnologías.

Previamente al comentario sobre su contenido, hay que destacar que no existe unanimidad por parte de la comunidad científica sobre la conveniencia, o no, de esta regulación avanzada. Por un lado, encontramos a quienes analizando críticamente la noción de neuroderechos del proyecto de Ley exponen toda una serie de debilidades jurídicas, así como de argumentaciones de carácter filosófico, para no legislar. A grandes rasgos señalan que se está regulando de manera apresurada, sin entender bien lo que se quiere proteger, y que el proyecto de Ley busca tutelar persistentes amenazas 
a los derechos humanos por medios equivocados ${ }^{29}$. Por el contrario, otros, aun señalando múltiples cuestiones a mejorar, lo valoran de manera positiva por su regulación escueta, con un marco acorde al momento, pero que posteriormente puede ser perfeccionado. No obstante, ambos sectores coinciden en que el contenido del proyecto pone al descubierto su finalidad, esto es, la neuromejoración del individuo. ${ }^{30}$

En todo caso el cuestionamiento de principio en torno a cualquier proyecto normativo de relevancia tal vez debiera someterse a un análisis previo a su remisión a las Cámaras. El cual, siguiendo a Atienza ${ }^{31}$, habría de llevarse a cabo en diferentes niveles de racionalidad a fin de examinar la eficacia y utilidad social y política de dichas reformas, de modo que acaben sirviendo al bien común.

Lo cierto es que el proyecto de Ley plantea cuestiones de carácter ético y filosófico no menores. Si bien estamos ante un proyecto que puede suponer un punto de partida para el desarrollo en otros países, el neuroesencialismo subyacente en la propuesta de la Neuroright Initiative, que considera que «por lo general creemos que somos nuestro cerebro» ${ }^{32}$, es una cuestión controvertida. Es la denominada «falacia mereológica» ${ }^{33}$, esto es, la confusión lógica que trata de vincular a las partes atributos que solo tiene sentido adscribir al ser humano como un todo. Por tanto, la regulación normativa debe considerar al ser humano en su integridad de cuerpo y mente, y no reducirlo únicamente a su soporte material, es decir, su cerebro, ya que es titular y portador de bienes morales y jurídicos inherentes a su naturaleza personal.

No obstante, como ha aclarado Yuste ${ }^{34}$, el espíritu de la Ley es aplicar el modelo médico — que ya se está empleando actualmente en neurotecnologías invasivas que requieren neurocirugía-, a las neurotecnologías no invasivas, puesto que el principal problema es que a día de hoy no están reguladas, por lo que gran parte de los riesgos que para los derechos humanos podría comportar su utilización se solucionaría incorporándolas dentro del sistema médico regulado con el Código Sanitario, y también aplicando la Ley de Trasplantes y de Donantes de Órganos. Ahora bien, no podemos obviar que, de acuerdo con los precedentes que ya conocemos en la sociedad digital, es de prever que muchas de estas tecnologías se presenten con un uso comercial o de ocio para el que difícilmente resultarán aplicables esos protocolos médicos, y que requerirán de otro tipo de respuesta.

29 ZÚÑIGA FAJURI, A., et al. (2020). «¿Neuroderechos? Razones para no legislar», CIPER $\mathrm{n}^{\circ}$ 20. Disponible en: https://www.ciperchile.cl/2020/12/11/neuroderechos-razones-para-no-legislar/.

30 DÍAZ FUENZALIDA, J.P. y PEREDO ROJAS, M.I. (2021). Cit. y ZÚÑIGA et al. (2020). Cit. ATIENZA, M. (1989). «Contribución para una teoría de la legislación», Doxa nº 6.

MOFFETT, S. (2008). El enigma del cerebro, Barcelona, Robin Book, p.276.

33 BENNETT M.R., HACKER, P.M.S. (2003). Philosophical Foundations of Neuroscience, Oxford, Blackwell.

34 YUSTE, R. (2020). Respuesta a las objeciones al proyecto de Ley en el Informe de la Comisión Congreso Del Futuro, 4 diciembre.

(C) UNED. Revista de Derecho Político

N. ${ }^{\circ} 112$, septiembre-diciembre 2021, págs. 415-446 


\subsubsection{El contenido introductorio}

El texto consta de una introducción excesivamente amplia y de redacción apresurada, donde se da cuenta de los avances en cuanto a las posibilidades de lectura y escritura en cerebros humanos, así como algunos ejemplos en el uso y aplicación de las neurotecnologías, estableciendo de este modo unas bases científicas que tratan de justificar la necesidad del reconocimiento de los neuroderechos; un camino que parte de las preocupaciones de la neuroética hasta llegar a la gobernanza política. No en vano se afirma «que la neurotecnología se erige como la ciencia donde se crearán nuevos derechos humanos, ante el debate ético y de seguridad que ha abierto». Podría pensarse que no deja de ser paradójico que, quienes están desarrollando estas tecnologías que pueden ser tan potencialmente dañinas para el ser humano, al mismo tiempo abanderen la causa para ponerles freno, aunque a dicha cuestión también cabría responder que quién conoce mejor las debilidades de su criatura que el propio creador. Como ha explicado Yuste en una de las muchas entrevistas realizadas a lo largo de $2020^{35}$, cuando Oppenheimer creó el proyecto Manhattan que produjo las primeras armas nucleares, también en el laboratorio de la Universidad de Columbia, fueron los propios físicos quienes alertaron inicialmente al Gobierno estadounidense sobre los peligros de esta tecnología.

Lo cierto es que no habría sido necesario dotar nuevamente de este ropaje científico al proyecto de ley, ya que el borrador de enmienda del artículo 19 n 1 contiene igualmente un extenso sustento teórico que expone la justificación de dicha reforma y, en consecuencia, de su desarrollo normativo. Sin embargo, sí se echa en falta una mayor reflexión introductoria en el plano jurídico, y más concretamente desde la dogmática constitucional; una carencia que se manifiesta también en su contenido respecto a la tutela sobre el avance neurotecnológico, que tendría que haber ido más allá, ampliando su aplicación a otros ámbitos de acción de los neuroderechos que no están mencionados y que son especialmente relevantes por la existencia de relaciones de desigualdad, como la actuación policial y las investigaciones judiciales, incluso en el ámbito de los derechos laborales. ${ }^{36}$ Además, no se menciona la Recomendación de la OCDE de 2019, que podría haberse consultado o servido de referencia.

\subsubsection{Los objetivos de la ley}

El título primero contiene las disposiciones generales donde se delimitan tres objetivos:

35 Disponible en: https://www.canalsur.es/multimedia.html?id=1649434

36 Así lo pone de manifiesto VARELA, A. (2020). Objeciones al proyecto de Ley en el informe de la Comisión Congreso Del Futuro, 04 de diciembre. 
a) Tutelar la integridad física y psíquica de las personas «a través de la protección de la privacidad de los datos neuronales, del derecho a la autonomía o libertad de decisión individual, y del acceso sin discriminaciones arbitrarias a aquellas neurotecnologías que conlleven aumento de las capacidades psíquicas».

b) Fomentar la «concordancia entre el desarrollo de neurotecnologías e investigación médico-clínica con los principios éticos de la investigación científica y médica y así sean favorables al bien y beneficio común».

c) Garantizar la «información a los usuarios de neurotecnologías sobre sus potenciales consecuencias negativas y efectos secundarios, y el derecho al control voluntario sobre el funcionamiento de cualquier dispositivo conectado a su cerebro».

Se definen así algunos de los neuroderechos (privacidad mental, libre albedrío, acceso al aumento de capacidades psíquicas sin discriminación) como garantías del artículo $19 \mathrm{n}^{\circ} 1$. No obstante, no se aclara el porqué de la intervención de sólo tres de los cinco propugnados (no se menciona ni la identidad personal ni tampoco la protección contra sesgos). A su vez, la garantía contenida en el epígrafe c) no deja de ser una más de las que persiguen finalmente tutelar esa integridad de la persona que recoge el objetivo a). Tampoco se entiende bien en qué medida podría proteger la integridad física y psíquica de las personas el acceso sin discriminación a neurotecnologías. ${ }^{37}$

\subsubsection{Las definiciones}

El título primero, a continuación de los objetivos, introduce «a los efectos de la ley», las definiciones de una serie de conceptos (artículo 2):

a) Neurotecnologías: Conjunto de dispositivos, métodos o instrumentos no farmacológicos que permiten una conexión directa o indirecta con el sistema nervioso.

b) Interfaz cerebro computadora (ICC): Sistema electrónico, óptico o magnético que mide la actividad del sistema nervioso central y la convierte en una salida conectada a una maquina o computadora, o que genera una respuesta artificial que reemplaza, restaura, complementa o mejora la respuesta del sistema nervioso natural y, por tanto, modifica las interacciones en curso entre el sistema nervioso y su entorno externo o interno.

37 DÍAZ FUENZALIDA, J. P. y PEREDO ROJAS, M. I. (2021). Cit. 
c) Datos neuronales: Aquella información obtenida, directa o indirectamente, a través de los patrones de actividades de las neuronas, cuyo acceso está dado por neurotecnología avanzada, incluyendo sistemas de registro cerebrales tanto invasivos como no invasivos. Estos datos contienen una representación de la actividad psíquica, tanto consciente como subconsciente, y que corresponden al más íntimo aspecto de la privacidad humana.

d) Neuroderechos: Nuevos derechos humanos que protegen la privacidad e integridad mental y psíquica, tanto consciente como inconsciente, de las personas del uso abusivo de neurotecnologías.

Las más problemáticas son las que definen los neuroderechos y las neurotecnologías. Zúñiga et al..$^{38}$ critican que el carácter novedoso de la definición de los neuroderechos parece solo ser resultado de la posibilidad de «un uso abusivo de neurotecnologías», al tiempo que consideran «curiosa» la distinción entre «integridad mental» e «integridad psíquica» porque las neurotecnologías no se caracterizan por su naturaleza, sino por su función o su eventual utilidad para obtener una conexión con el sistema nervioso, lo cual no limita su acción al puro cerebro, y lo cierto es que son muchos los avances tecnológicos que, a lo largo de la historia, ya han modificado nuestro comportamiento y alterado la identidad personal y el libre albedrío. A ello habría que añadir que el propio concepto resulta contradictorio, puesto que mientras el primer objetivo del proyecto contempla la privacidad mental como un mecanismo de garantía de la integridad, en la conceptualización, los neuroderechos tutelan ambos bienes jurídicos: "protegen la privacidad e integridad mental y psíquica, tanto consciente como inconsciente, de las personas del uso abusivo de neurotecnologías».

Posiblemente el término en su sentido fundacional — cinco nuevos derechos humanos que se pretenden agregar a la $\mathrm{DUDH}^{39}$ —, pese a la potencialidad mediática que encierra es, al tiempo, un obstáculo en su traslación al ordenamiento interno, donde como vemos se está trabajando sobre las garantías de los derechos clásicos, actualizando para ello la Constitución, así como con una Ley de desarrollo. Además, evidencia un neurodeterministo que el derecho a priori rechaza, ya que los derechos son los del ser humano en su integridad, cuerpo y mente, y no solo de una de estas facetas.

En las enmiendas al proyecto de Ley se ha propuesto reelaborar algunos conceptos. Por ejemplo, una nueva definición de neuroderechos como: «derechos fundamentales de la persona que protegen su integridad física y psíquica y la privacidad de sus datos neuronales, tanto consciente como inconsciente, del uso y aplicación de neurotecnologías, especialmente ante un eventual uso o aplicación abusiva de

38 ZÚÑIGA FAJURI, A. et al. (2020). Cit.

39 El primer objetivo de la Fundación NeuroRights es proteger los derechos humanos de todas las personas del posible uso indebido o abuso de la neurotecnología. Disponible en: https://plum-conchdwsc.squarespace.com/mission 
ellas» ${ }^{40}$; neurotecnologías como: «conjunto de dispositivos, métodos o instrumentos que permiten una conexión directa o indirecta con el sistema nervioso»; y datos personales neuronales como «aquellos datos personales obtenidos directa o indirectamente de los patrones de actividades de las neuronas utilizando para ello neurotecnologías. Estos datos contienen una representación de la actividad cerebral, tanto consciente como subconsciente». ${ }^{41}$

Creemos que en la labor conceptualizadora habría sido conveniente contemplar las definiciones recogidas por la Recomendación de la OCDE en este ámbito. Por ejemplo, respecto de los «datos neuronales» que la Recomendación define como: «aquellos datos relacionados con el funcionamiento o la estructura del cerebro de un individuo identificado o identificable, incluida información única sobre su fisiología, salud o estado mental», el proyecto de Ley chileno resulta más comprensivo puesto que, como se expresa, estos datos «contienen una representación de la actividad psíquica, tanto consciente como subconsciente, y que corresponden al más íntimo aspecto de la privacidad humana», lo que comprendería — y a su vez sería objeto de protección- no sólo datos de salud o estado mental, sino también recuerdos, sentimientos o incluso emociones. Aun así, se ha pedido ampliar dicha definición, puesto que hoy en día existen otras técnicas que pueden recoger aspectos de la actividad cerebral como los flujos sanguíneos. ${ }^{42}$

Por último, se ha propuesto la introducción de otros conceptos, como neurotecnologías con fines curativos, neurotecnología extrapotencial y neurotecnología intrapotencial. ${ }^{43}$

\subsubsection{Las prohibiciones legales y los límites del consentimiento}

El segundo título incorpora la prohibición de utilizar neurotecnologías en las personas sin el debido consentimiento (artículo 3), así como de aquellas que puedan dañar o limitar la identidad individual o el libre albedrío, a excepción de las contempladas en los casos de investigación o terapia médica, a las que se aplicará el código sanitario vigente (artículo 4). A su vez establece una serie de requisitos para el formulario del consentimiento (artículo 5), la consideración de los datos neuronales como datos sensibles de salud (artículo 6), así como la aplicación de la Ley sobre trasplantes y donación de órganos a los datos neuronales y la actividad cerebral (artículo 7).

Respecto de la regulación del consentimiento, se valora positivamente que éste se establezca como base para que las intervenciones de neurotecnologías sean válidas, así como la obligación expresa de informar previamente sobre sus eventuales efectos,

\footnotetext{
40 Senador COLOMA (2021). Boletín indicaciones al proyecto de ley, 05 abril.

41 Presidente de la República PIÑERA, S. (2021). Boletín indicaciones al proyecto de ley, 05 abril.

42 MALDONADO, P. (2020). Objeciones al proyecto de Ley en el informe de la Comisión Congreso del Futuro, 04 de diciembre.

43 Senador COLOMA (2021). Boletín indicaciones al proyecto de ley, 05 abril.
} 
para garantizar así la voluntad libre de quienes se sometan a ellas, aunque su regulación debe respetar en todo caso los límites del derecho fundamental a la integridad física y psicológica «lo cual se beneficiaría de una determinación del contenido esencial de la integridad neurológica, lo que no ocurre en el proyecto de reforma constitucional» ${ }^{44}$. No obstante se considera que el término «conexiones neuronales», contenido en el artículo 3, debería modificarse, siendo más adecuado hablar de intervención de la «comunicación neuronal», al ser más amplio ${ }^{45}$. A su vez se ha cuestionado cuáles serán las garantías de las personas afectadas para que el consentimiento pueda ser absolutamente libre e informado ${ }^{46}$.

Mayor controversia plantea el artículo 4, ya que introduce conceptos como identidad personal o libre albedrío, de difícil definición. Por una parte se establece la prohibición de dispositivos de neurotecnología que dañen la identidad individual, que equiparan a «la continuidad psicológica y psíquica de la persona». Aunque resulta positivo que se establezca una prohibición absoluta a cualquier intervención que dañe o altere el derecho, en esencia, a la personalidad y dignidad humana, la equivalencia entre «identidad» y «continuidad» debería considerarse limitada al ámbito de la intervención de las neurotecnologías, sin confundirse con una definición general y que trasciende la materia, debiendo entenderse como lex specialis ${ }^{47}$. Esta prohibición también actuaría sobre aquellas neurotecnologías que disminuyan o dañen la autonomía de la voluntad o capacidad de toma de decisión en libertad. Sin embargo, el libre albedrío tiene múltiples dimensiones y actualmente plantea varios problemas filosóficos aún por resolver, como su compatibilidad con el determinismo, o la influencia de la diversidad cultural en su interpretación, por lo que debe trabajarse para desarrollar una definición mínima y consensuada que ayude a evitar malas interpretaciones basadas en lagunas normativas. ${ }^{48}$

Otra inconsistencia radicaría entre el mensaje y el articulado propuesto, ya que además de los enunciados prohibitivos no se contiene norma que defina un derecho subjetivo, por lo que Zúñiga et al. se preguntan cómo es posible que un proyecto que busca defender neuroderechos no contemple derechos subjetivos, criticando así «el desequilibrio entre el escrúpulo con que se alcanzan resultados en neurobiología y la ligereza con que se adoptan las categorías que la ciencia jurídica ha tomado siglos en discernir ${ }^{49}$.

44 DÍAZ FUENZALIDA, J. P. y PEREDO ROJAS, M. I. (2021). Cit.

45 MALDONADO, P. (2020). Objeciones al proyecto de Ley en el informe de la Comisión Congreso Del Futuro, 4 de diciembre.

46 VARELA, A. (2020). Objeciones al proyecto de Ley en el informe de la Comisión Congreso Del Futuro, 4 de diciembre.

47 DÍAZ FUENZALIDA, J. P. y PEREDO ROJAS, M. I. (2021) Cit.

48 MUÑOZ, José M., (2019). «Chile - el derecho al libre albedrío necesita una definición», Nature $\mathrm{n}^{\circ} 574$.

49 ZÚÑIGA FAJURI, A. et al. (2020). Cit. En el mismo sentido, la Carta de Derechos Digitales española tampoco reconoce derechos específicos. 
Algunas cuestiones que se han planteado al artículo 4 tienen que ver con el carácter limitado o absoluto del reconocimiento del derecho a la privacidad mental y la continuidad psicológica, puesto que el proyecto no se pronuncia explícitamente sobre si estamos ante un derecho absoluto o relativo. En este sentido no existe acuerdo en la literatura neuroética, que ha considerado justificadas determinadas intromisiones, cuando el interés público está en juego y con una orden judicial ${ }^{50}$.

Otro interrogante se abre respecto al límite entre lo farmacológico y la neurotecnología, puesto que la actividad cerebral puede ser conocida no solo a través de la medición de la actividad neuronal, sino también mediante otros mecanismos, lo cual debería ser considerado en el proyecto. ${ }^{51}$ No obstante, se aclara que en el mismo se definen estas tecnologías en tanto no farmacológicas, puesto que las que lo son ya están cubiertas por el Código Sanitario; de manera que lo que se pretende es reforzar el tejido existente de regulación médica con un tipo nuevo de tecnologías que han aparecido, y que vienen asociadas a la electrónica de consumo. ${ }^{52}$

Por último, se plantea completar esta prohibición estableciendo una multa de 1 a 100 unidades tributarias mensuales a quien colabore, implemente o se someta a neurotecnologías que dañen a la persona ${ }^{53}$; la prohibición de intervención en menores de 18 años, excepto aquellas con fines $\operatorname{curativos}^{54}$; o la prohibición de usar neurotecnologías en investigaciones penales contra la voluntad del imputado, la víctima o el testigo implicado, así como de beneficios procesales o penitenciarios para quien se someta a estos sistemas. ${ }^{55}$

Sobre el formulario donde se solicite el consentimiento (artículo 5), se ha planteado la objeción de que resulta bastante complicado abordar todos los posibles efectos físicos de su aplicación, así como los eventuales efectos cognitivos y emocionales, siendo difícil elaborar una lista completa y adecuada de los mismos con el conocimiento que tenemos a día de hoy sobre el sistema nervioso, obligación que probablemente frenaría propuestas de neurotecnologías, ya que no siempre podría ser posible cumplir este título. ${ }^{56}$

El artículo 6 introduce una modificación en la Ley $n^{0} 19.628$ sobre la Vida Privada de las Personas, estableciendo que los datos neuronales constituyen una categoría específica de dato sensible de salud. Por su parte, el artículo 7 señala que la recopilación, almacenamiento, tratamiento y difusión de los datos neuronales y

50 IENCA M. y ANDORNO R. (2017). «Towards new human rights in the age of neuroscience and neurotechnology». Cit.

51 MORALES, B. (2020). Objeciones al proyecto de Ley en el informe de la Comisión Congreso Del Futuro, 4 diciembre.

52 YUSTE, R. (2020). Objeciones al proyecto de Ley en el informe de la Comisión Congreso Del Futuro, 4 diciembre.

53 Senador GARCÍA, senador PUGH (2021). Boletín indicaciones al proyecto de ley, 5 de abril.

54 Senador COLOMA (2021). Boletín indicaciones al proyecto de ley, 5 de abril.

55 Senador GARCÍA, senador PUGH (2021). Boletín indicaciones al proyecto de ley, 5 de abril.

56 MALDONADO, P. (2020). Objeciones al proyecto de Ley en el informe de la Comisión Congreso del Futuro, 4 de diciembre. 
la actividad neuronal de las personas se ajustará a las disposiciones contenidas en la Ley 19.451 sobre Transplante y Donación de Órganos, en cuanto le sea aplicable, así como las previsiones del Código Sanitario respectivas. Se incorpora en este sentido una modificación del artículo 145 del Código Sanitario, que en su actual redacción establece: «El aprovechamiento de tejidos o partes del cuerpo de un donante para su injerto en otra persona sólo se permitirá cuando fuere a título gratuito o con fines terapéuticos», para agregar la siguiente oración final, nueva: «Lo mismo aplicará para el aprovechamiento de la actividad neuronal y los datos neuronales obtenidos a partir de ella». Se pide, además, que el tratamiento de los datos esté sujeto a una serie de principios: finalidad, reserva o secreto, calidad, seguridad ${ }^{57}$, y que se incorpore un nuevo inciso que reconozca que toda persona tendrá derecho a la privacidad de sus datos neuronales. ${ }^{58}$

Finalmente, en cuanto al artículo 7 sobre la protección de los datos neuronales, se solicita sustituir su redacción por un nuevo texto donde se introduzca el derecho al no envío automático de los datos cerebrales ni la extracción forzosa de datos recopilados, con la única excepción de las investigaciones penales, previa autorización judicial. ${ }^{59}$

\subsubsection{Límites y obligaciones estatales ante el desarrollo de las neurotecnologías}

En este tercer título se establece que todas aquellas actividades científicas cuyo enfoque sea el estudio y/o desarrollo de neurotecnologías que permitan conectar directamente dispositivos con el sistema nervioso tendrán siempre como límite la integridad física y psíquica de las personas (artículo 8). Esta limitación resulta cuestionable, ya que el deseo de aumentar la neurocognición y ser parte de una élite social-tecnológica podría perpetuar brechas y dar paso a la evolución de una sola porción de la sociedad ${ }^{60}$. Es decir, además de esa limitación al respecto de la integridad, es evidente que también puede tener un gran impacto en el principio de igualdad y no discriminación, incluso otros derechos humanos pueden verse igualmente afectados, como ya se advirtió, por lo que plantear el límite exclusivamente en la integridad resulta insuficiente.

Al mismo tiempo se incorporan una serie de obligaciones del Estado, o más bien recomendaciones dados los verbos «propenderá» o «velará» empleados, con la finalidad de promover el desarrollo de neurotecnologías que velen por el interés y bien público (artículo 9) ${ }^{61}$, y la promoción del acceso equitativo a estos avances (artículo 10), pero quedan fuera otros principios como la educación, o la responsabilidad que

\footnotetext{
57 Presidente de la República, PIÑERA, S. (2021). Boletín indicaciones al proyecto de ley, 05 abril.

58 Senador COLOMA (2021). Boletín indicaciones al proyecto de ley, 05 abril.

59 Senador COLOMA (2021). Boletín indicaciones al proyecto de ley, 05 abril.

60 DÍAZ FUENZALIDA, J. P. y PEREDO ROJAS, M. I. (2021). Cit.

${ }_{61}$ Presidente de la República, PIÑERA, S. (2021). Boletín indicaciones al proyecto de ley, 05 abril.
} 
se exigirá al Estado por el uso indebido de estas neurotecnologías, sin quedar claro cuáles serían las vías procesales ante incumplimientos de la normativa ${ }^{62}$. Al igual que la redacción del articulo 10 resulta insuficiente, puesto que las posibilidades de aumento cognitivo que se abren podrían incrementar las desigualdades, produciéndose «ciudadanos de primera y segunda categoría», recomendando por tanto «agregar normas que establezcan la obligación del Estado no solo de garantizar un acceso igualitario a prestaciones, sino también de garantizar un igual trato entre sujetos dotados de mejoras neurotecnológicas, frente a aquellos que no las han recibido» ${ }^{63}$. Otra cuestión, incluso, sería cómo garantizar el acceso, o en qué casos, o para cuáles usos, o bien si el Estado no sólo ejercería un papel tutelador sino directamente prestacional, con el coste económico correspondiente.

Otro tema polémico es el transhumanismo, y si merece elevarse a la categoría de derechos fundamentales y humanos. Del mismo modo que la edición genética con fines de mejora no se entiende como algo deseable en la actualidad, ni es permisible en los ordenamientos jurídicos, la misma postura debería adoptarse frente a la mejora cognitiva con neurotecnologías, debiendo limitarse el acceso equitativo sólo a neurotecnologías con fines terapéuticos, hasta que no se promueva una gran participación y deliberación internacional, dejando claro que no se está dando vía libre. ${ }^{64}$

Asimismo debería explicarse qué significa que el Estado vele por la promoción del acceso equitativo, y si aquel debería financiar la incorporación de tecnologías en los ciudadanos, es decir, cómo se traducirá o cómo se velará por este «acceso equitativo», puesto que el desarrollo de las neurotecnologías va a ocurrir, pero eso no significa que el Estado deba poder costear el acceso; incluso cómo se va a verificar el cumplimiento de esta ley, o el propio significado de «acceso» ${ }^{65}$. De nuevo, la respuesta sobre el aumento sensorial y cognitivo, como expone Yuste ${ }^{66}$, es pasar la decisión a los médicos, igual que se hace con los trasplantes de órganos, explicando que no es una opción que dependa del individuo o de sus recursos económicos, sino que se tomará conforme a principios generales de justicia, basados en el Código Sanitario. Como ya hemos comentado, entendemos que la regulación desde el ámbito médico se queda corta para el grado de difusión y profundización en el uso social que previsiblemente tendrán las neurotecnologías.

62 DÍAZ FUENZALIDA, J.P. y PEREDO ROJAS, M.I. (2021). Cit.

63 DÍAZ FUENZALIDA, J.P. y PEREDO ROJAS, M.I. (2021). Cit.

64 BORBÓN RODRIGUEZ D. A. (2021). «Reforma de los NeuroDerechos Humanos en Chile: Comentarios frente a la mejora cognitiva y el posthumanismo», Blog Derechos humanos y empresas de la Universidad Externado de Colombia, 16 de mayo.

Disponible en: https://derechos-humanos-y- empresas.uexternado.edu.co/autor/diego-borbon-rodriguez

65 MALDONADO, P. (2020). Objeciones al proyecto de Ley en el informe de la Comisión Congreso Del Futuro, 04 diciembre.

66 YUSTE, R. (2020). Objeciones al proyecto de Ley en el informe de la Comisión Congreso Del Futuro, 04 diciembre.

(C) UNED. Revista de Derecho Político

N. ${ }^{\circ} 112$, septiembre-diciembre 2021, págs. 415-446 
Por último, se plantea incorporar al borrador del proyecto de Ley un título cuarto para la creación de un Consejo Nacional de Neurociencia que vele por la seguridad de las personas y de su integridad en este ámbito de investigación. ${ }^{67}$ Consideramos positiva la existencia de este tipo de organismos de control y seguimiento que se complemente con los límites introducidos en el propio desarrollo normativo, una propuesta que va en la línea de las recomendaciones realizadas por Yuste a la ONU, para la creación de organismos de asesoramiento y control en esta materia.

\section{REFLEXIONES FINALES}

Aunque aún está por ver si las propuestas se incorporan finalmente a sus respectivos ordenamientos jurídicos, el balance general de los pasos dados hasta ahora es positivo. De un lado, el debate generado en sede parlamentaria y en los expertos está contribuyendo a tomar conciencia de los beneficios y riesgos de las nuevas tecnologías, así como de las formas de afrontarlos. Por otro, las ideas y objeciones que ya se han planteado podrán servir como punto de partida en terceros países que, al menos, cuentan con estos intentos de regulación como referencia.

Hay que aplaudir la incorporación de la ciencia a la gobernanza. La complejidad del mundo moderno demuestra que sus aportaciones resultan imprescindibles en la consecución del bienestar colectivo.

La crítica más frecuente a la propuesta de los neuroderechos ha sido la de que se está intentando regular sin saber muy bien cuáles serán los efectos de las neurotecnologías en las personas, incluso sin que estas se hayan impuesto aún en el uso cotidiano, desconociendo sus implicaciones en los derechos humanos. Pero, como ha advertido Yuste, cuando las tecnologías emergen es mucho más fácil regularlas que cuando ya se han consolidado. Adoptar una regulación ex ante, aun con sus imprecisiones, podría ser de gran utilidad, permitiendo «que el regulador competente disponga de una amplia paleta de instrumentos para intervenir preventivamente frente a los gigantes digitales, lo que incluiría una lista de prácticas prohibidas (...).» ${ }^{68}$.

De ahí que nos parezca acertado este comienzo. Posiblemente no sea una labor imprescindible en estos momentos pero, al ritmo que avanza la tecnología, es de prever que, si no lo hacemos ahora, podamos llegar tarde una vez más, con los consiguientes riesgos para los derechos humanos y el propio sistema democrático.

Como hemos visto, voces autorizadas desde la ciencia, o la gobernanza de países como Chile o España, incluso instituciones internacionales, han apostado ya por regular con el fin de anticiparse a estas tecnologías capaces de interactuar con el cerebro y evitar problemas inesperados que puedan surgir en entornos en los que actualmente no existe legislación específica.

${ }^{67}$ Senador COLOMA (2021). Boletín indicaciones al proyecto de ley, 05 abril.
68 INNERARITI, D. (2021). «Regular la digitalización», La Vanguardia, 10 de abril. 
Ahora bien, el avance regulativo no puede estar liderado, exclusivamente, desde la política y la ciencia. Es imprescindible la actuación del derecho, siendo una de sus funciones la de ofrecer respuestas frente al cambio social, por tanto éste debe intervenir, incluso cuando estos cambios se estén aún gestando, señalando el camino, estableciendo límites éticos, sin que ello tenga que generar prejuicios, máxime en este ámbito. Una interacción que ha de tener presente la perspectiva constitucional y también filosófica puesto que la constatación de ciertos descubrimientos por la ciencia, máxime de esta envergadura, no puede concluir con la elaboración de normas sin un previo examen desde la teoría del derecho, y más concretamente desde la teoría del derecho constitucional.

Una objeción habitual que encontramos cuando hablamos de nuevos derechos tiene que ver con la idea de que una proliferación injustificada propaga el escepticismo sobre todos los derechos humanos produciéndose una «inflación de derechos». En nuestra doctrina, mientras una parte defiende la tesis de que los derechos humanos han de ser pocos si se les ha de atribuir una especial fuerza moral ${ }^{69}$, otra parte argumenta que una mayor extensión de los mismos va acompañada de una mayor intensidad en su protección ${ }^{70}$. Lo cierto es que lo que se debe demostrar es su exigibilidad, mediante pruebas justificativas para derechos humanos específicos ${ }^{71}$. En este sentido, la propuesta de Ienca y Andorno ${ }^{72}$ argumenta las razones por las cuales tanto los nuevos derechos propugnados como la reconceptualización de los clásicos reúnen dichos requisitos y, por tanto, no aumentarían el riesgo de inflación.

A su vez, pensar en neuroderechos no puede hacerse si no es desde el espacio internacional, donde se hace preciso un debate sobre su reconocimiento. El consenso sería importante para que aquellos países que, como Chile o España, ya han comenzado el proceso de regulación no queden en desventaja estratégica respecto a otros con menos restricciones. ${ }^{73}$ No obstante, algunos límites derivados de principios jurídicos básicos del ordenamiento internacional, tales como la igualdad soberana de los Estados, o la no injerencia en los asuntos internos, podrían dificultar o ralentizar estos acuerdos, máxime teniendo en cuenta la heterogeneidad cultural de aquellos. Ello confirma que la acción individual, aun con la desventaja económica que ello pudiera suponer, debe imponerse en paralelo con la vía internacional.

Las propuestas chilena y española nos muestran dos formas diferentes de regulación. En el caso de Chile, se aborda desde arriba hacia abajo, partiendo de la reforma constitucional. Ahora bien, en los debates de las Cámaras se echa en falta una mayor

69 LAPORTA, F. (1987). «Sobre el concepto de derechos humanos», Doxa nº 4, p. 23.

70 PEREZ LUÑO, A. (1987). «Concepto y concepción de los derechos humanos. Acotaciones a la Ponencia de Francisco Laporta», Doxa no 4, p. 61.

71 HIERRO SÁNCHEZ PESCADOR, L. (1999). «¿Qué derechos tenemos?», Doxa n 23, p. 354.

72 IENCA M., ANDORNO R. (2017). «Towards new human rights in the age of neuroscience and neurotechnology», Cit.

73 WAJNERMAN, A. (2021). "¿Por qué importa el avance de las iniciativas sobre neuroderechos?», La Tercera, 19 abril 2021. 
reflexión sobre la necesidad, o no, de la misma. Si bien la reforma de la Ley 21.096, de 16 de junio de 2018, otorgó explícitamente rango constitucional a la protección de datos personales, por lo que podría pensarse que la tutela constitucional de intereses vinculados con la intimidad y la inviolabilidad de las comunicaciones ya estaría consagrada en el art. 19.4 de la Constitución, como así ha defendido reputada doctrina $^{74}$, tal afirmación se apoya en dos presupuestos que a su vez plantean algunos interrogantes.

El primero parte de considerar los datos cerebrales solo como un tipo específico de dato personal, con independencia del soporte en el que este se encuentre. Sin embargo, como se ha advertido ${ }^{75}$, incluso en el Reglamento Europeo de Protección de Datos (RGPD) no parece estar clara la categorización de datos cerebrales obtenidos por aplicaciones comerciales de ICC y, sin embargo, estos son tan sensibles como los datos de salud, por lo que es preciso regular que cualquier dato cerebral se categorice, al igual que los datos médicos, como confidencial y de protección especial por el alto potencial que tienen para identificar personas y revelar características sensibles a través de su procesamiento. Pero incluso ello podría ser insuficiente, ya que probablemente el modelo de negocio para los datos cerebrales se base en el consentimiento y para esto, el RGPD actual, y la política en general, no ofrece soluciones satisfactorias. Los riesgos persistirán, en este contexto, con datos altamente sensibles en juego.

El segundo presupuesto parte de que la protección de los neuroderechos habría de ubicarse en el ámbito de la privacidad. Sin embargo, como ya se ha advertido, existen otros derechos fundamentales, que también podrían verse afectados por el uso indebido de las neurotecnologías, por lo que, a priori, parece más amplia su inclusión en el apartado dedicado a la integridad, por su potencial para impactar o generar un daño en la red neuronal, incluso alterar la propia identidad personal. ${ }^{76}$

Por el contrario, en el caso español, la regulación se concreta en una carta sin valor vinculante, que se presenta como una guía de actuación para los poderes públicos. El nivel de compromiso de cada país, como puede deducirse, es bien distinto. Ello nos lleva a pensar sobre cómo regular en la sociedad del Big Data, ya que no solo creemos que puede ser positivo adelantarse en la normativa, sino que al mismo tiempo tienen que establecerse políticas comprometidas que marquen líneas rojas y establezcan mandatos de obligado cumplimiento. Para hacer frente a los riesgos que nos vienen, y estando en juego los derechos humanos, el derecho blando o las propuestas de autorregulación de las empresas no resultan suficientes.

74 LOPEZ SILVA, P. y MADRID, R. (2021). «Sobre la conveniencia de incluir los neuroderechos en la Constitución o en la ley», Revista Chilena de Derecho y Tecnología 10, n. ${ }^{\circ}$ 1, p. 63.

75 RAINEY, S., et al. (2020). «Is the European Data Protection Regulation sufficient to deal with emerging data concerns relating to neurotechnology?», Journal of Law and the Biosciences.

76 IENCA M., ANDORNO, R. (2017), «Towards new human rights in the age of neuroscience and neurotechnology». Cit. 
Para concluir, en cuanto al reconocimiento de nuevos derechos o la reconceptualización de los clásicos — al fin y al cabo, expresión de los valores de libertad e igualdad-, creemos que el acento debe ponerse en dos cuestiones:

En primer lugar, al hilo de cómo debemos regularnos en la sociedad digital, y si es preciso reconfigurar el pacto constitucional, hay que hacer una nueva lectura de sus valores y principios. Desde una perspectiva filosófica existen dos grandes posturas para enfrentarnos a las nuevas tecnologías. Por un lado, los bioconservadores, que subrayan las consecuencias desastrosas que los avances tecnológicos pueden producir a la humanidad y al medio ambiente; por otro, los transhumanistas, que pretenden emplear la tecnología para mejorar la vida de las personas y para resolver los problemas sociales contemporáneos. El constitucionalismo no debe dar la espalda a tales cuestiones, puesto que estas distintas posiciones pueden tener una traslación en cuanto a la forma de articular regulaciones ante los nuevos contextos. Nos enfrentamos a la disyuntiva de si, como hasta ahora, legislar desde el reconocimiento de aquellos valores superiores y principios para protegerlos o si, como parecen demandar las grandes tecnológicas, posibilitar técnicas que, de manera horizontal, sin valores identificados, establezcan la norma en base a cómo ha de ser la tecnología. En este sentido, no solo vamos a necesitar pensar en nuevos derechos o en un replanteamiento de los clásicos, sino que también debemos centrarnos en aquellos valores sociales que habrían de regir las infraestructuras, ya que la tecnología no entiende al individuo, es colectivista. ${ }^{77}$

Pero al mismo tiempo, creemos que los poderes privados tienen que convertirse también en protagonistas imprescindibles del pacto constitucional en esta era digital. Debemos preguntarnos si avanzamos hacia pactos regulatorios con plataformas tecnológicas y con otros actores, incluso explorar alianzas por el interés general con empresas más poderosas que nuestros Estados-nación, presionando para que se adhieran a códigos éticos. Y todo ello sin perder de vista el liderazgo de los poderes públicos, pues en último término son los directamente legitimados desde el punto de vista democrático. Un ejemplo en ese sentido sería el juramento tecnocrático en el que ya trabajan la empresa Sherpa.ai junto con la Universidad Católica de Chile según la propuesta del Morningside Groupe. O si, por el contrario, no podemos afrontar los riesgos por los usos indebidos de estas nuevas tecnologías utilizando solo enfoques de derecho indicativo, o mecanismos de autorregulación de las empresas, sino que necesitamos políticas que den prioridad a los derechos fundamentales y establezcan líneas infranqueables y obligaciones estrictas.

Se hace por tanto preciso reflexionar sobre la constitucionalización del espacio privado, o más bien, una posible reconfiguración del pacto constitucional compartido entre los poderes públicos y privados.

77 JAUME PALASí, L. (2020). Presentación del resultado de los grupos de trabajo de la Carta de Derechos Digitales, 17 de noviembre. Disponible en: https://digitalfuturesociety.com/es/agenda/carta-derechos-digitales-streaming/

(C) UNED. Revista de Derecho Politico

N. ${ }^{\circ} 112$, septiembre-diciembre 2021, págs. 415-446 
Un segundo aspecto es el de las garantías que han de regir para que los poderes públicos y privados no dañen o alteren derechos fundamentales mediante el uso de la tecnología, por ejemplo, estableciendo límites o prohibiciones legales, creando organismos autónomos de vigilancia o control; incluso potenciando nuevos desarrollos tecnológicos que tutelen los derechos fundamentales. Además, la vertiente prestacional del Estado se hace imprescindible para la protección de estos derechos clásicos de libertad en su proceso de reconceptualización. En este sentido, la pandemia mundial ocasionada por la Covid-19 nos ha alumbrado un precedente esperanzador: en una situación de claro riesgo de orden global, el ser humano ha conseguido, por vía de la investigación científica, encontrar una solución y emplearla desde principios democráticos, de manera igualitaria, y bajo criterios médicos y de orden social.

En resumen, y utilizando las palabras del rabino y maestro judio Hilel el Sabio, «si no lo hacemos ahora, cuándo, si no lo hacemos nosotros, quién», y es que no podemos dejar en manos de las generaciones futuras la regulación de unas tecnologías que se transformarán —y transformarán nuestra vida — día a día, en muchas ocasiones de manera casi imperceptible y presentadas bajo el amable reclamo de estímulos publicitarios. Tal vez en ese momento sea, en efecto, demasiado tarde, y quizá entonces debamos preguntarnos si queremos que el derecho sea un mecanismo paliativo de efectos indeseados, o anteponiéndose a ellos, permita un desarrollo tutelado de todo aquello que en definitiva nos haga más felices.

Title:

New rights against neurotechnology: the Chilean experience

\section{Summary:}

1. INTRODUCTION. 2. THE ORIGIN OF NEURORIGHTS. 3. CHILE, THE PIONEER IN REGULATING NEURORIGHTS. 3.1. The constitutional reform initiative. 3.1.1. The first constitutional procedure: deliberation and approval before the Senate. 3.1.2. The second constitutional procedure: deliberation and approval before Congress 3.2. The bill on the protection of neuro-rights. 3.2.1. Introductory content. 3.2.2. The objectives of the law. 3.2.3. The definitions. 3.2.4. Legal prohibitions and limits of consent. 3.2.5. Limits and state obligations before the development of neurotechnologies. 4. FINAL REFLECTIONS. 


\title{
Resumen:
}

Chile, en el marco de un nuevo proceso constituyente, aborda en primicia la reforma del artículo $19 \mathrm{n}^{\circ} 1$ de su Constitución para hacer frente a los usos indebidos de las neurotecnologías, una enmienda que se desarrolla a través de un proyecto de Ley en el que se reconocen los conocidos como «neuroderechos», en terminología acuñada en la Neuroright Initiative de la Universidad de Columbia, New York, y que dirige el neurobiólogo español Rafael Yuste. En este artículo se analiza el proceso legislativo y sus enmiendas, con la finalidad de profundizar en el debate acerca de la regulación de las neurotecnologías reivindicando la presencia necesaria del derecho constitucional.

\begin{abstract}
:
Chile, within the framework of a new constituent process, addresses firstly the reform of article 19.1 of its Constitution to cope with the misuse of neurotechnologies, an amendment that is developed through a draft bill that recognizes the "neurorights» in terminology coined at the Neuright Initiative of Columbia University, New York, and directed by the Spanish neurobiologist Rafael Yuste. This article analyzes the legislative process and its amendments, in order to deepen the debate about the regulation of neurotechnologies, claiming the necessary presence of constitutional law.
\end{abstract}

\section{Palabras clave:}

Neuroderechos, proceso constituyente, Chile, neurotecnologías, derecho constitucional.

\section{Keywords:}

Neurorights, constituent process, Chile, neurotechnologies, constitutional law. 
